eight months. I injected the urethra with muddy water every other morning for ten days, when the discharge ceased. The rheumatic pains ceased also, supporting, therefore, my friend Dr. Boud's theory of the cause of gonorrbœal rheumatism. This patient took iron and arsenic in small doses, as he was somewhat anæmic.

The freedom from pain, the destruction of all odour from the wound, the diminution of the discharges, and the rapid healing after the application of the earth, were the features common to all these cases which impressed me most.

Dr. Hewson, who will shortly visit England, believes the action of the earth mainly a chemical one, and he covers his dressing with blue paper in order that the chemical rays of light may be admitted to the wound.

I am, Sir, your obedient servant,

Venice, May 17th, 1873. JósePH Groves, B.A., M.B. Lond.

\section{CLINICAL THERMOMETERS AND THEIR DEVIATIONS.}

To the Editor of THE Lavaet.

SiR,-The re-discovery by Mr. Kesteven of the fact that clinical thermometers vary much in the indications which they afford will, it is to be hoped, prevent any one from purchasing one of these instruments unaccompanied by its certificate of verification.

The errors to which all clinical thermometers are liable, and the necessity that exists for their verification at one of the observatories, were pointed out by me in a paper read before the British Medical Association in 1869.

I have several times found, on placing half a dozen of these thermometers in a basin of warm water, that, they have all furnished different readings. Dr. Prior, of Bedford, related some years ago an experiment of comparison which he made with five thermometers, three of them being medical instruments. He plunged them all in water at a temperature of $105^{\circ}$ or $106^{\circ} \mathrm{F}$, and allowed it gradually to cool. The result is given in bis own words: "No two of them precisely corresponded at any time."

What are the principal causes of the errors of clinical thermometers?

1. A difference in the diameter of the bore throughout their length. In consequence of this defect, which seems at present almost unavoidable in their manufacture, the majority of clinical thermometers indicate a temperature sometimes higher, sometimes lower, at other times higher in one part of the scale and lower in another part, than is correct. Here, for example, is a copy of a certificate belonging to one of my clinical thermometers, which not only reads too high, but posseeses a bore of unequal size:"At $85^{\circ}-0.3^{\circ}$; at $90^{\circ}-04^{\circ}$; at $95^{\circ}-0.5^{\circ}$; at $100^{\circ}-0.4^{\circ}$; at $105^{\circ}-0.4^{\circ}, "$

2. A contraction of the glass bulb.-The bulb, having been formed by the aid of heat, undergoes contraction, the fibres of the glass taking some little time to assume their permanent position. Hence it has been usual amongst some makers of meteorological instruments to lay down their thermometers, like their port, for improvement with age. In consequence of this change in the glass, clinical thermometers are apt to read higher as they become older. The alteration in the bulb especially occurs during the year or two immediately succeeding the period of their construction.

What precautions should be taken in order to ensure the possession of trustworthy instruments?

A clinical thermometer unprovided with a certificate of its recent verification at either the $\mathrm{Kew}$ or Greenwich Observatories should never be purchased. The corrections, if any, contained in the certificate, should be applied to each observation that is made.

Those who have employed unverified clinical thermometers should send them to Kew to be verified. A trifling fee is charged by the authorities for the examination of each instrument.

Manufacturers of clinical thermometers should not engrave the scale on the tubes of their thermometers until they have been filled with mercury for at least two years.

It must be remembered, however, that the verification of a two- or three-year old thermometer at an observatory cannot be relied on as a guarantee of the perpetual accuracy of an instrument. The following note is very properly appended to all the certificates issued at $\mathrm{Kew}:$ - "This instrument ought at some future date to be again tested at the melting-point of ice, and, if its reading at that point be found different from that now given, an appropriate correction ought to be applied to all the above points."

I remain, Sir, yours faithfully,

Corneluos B. Fox, M.D., M.R.C.P. Lond. Fellow of the British and Member of the Scottish Scarborough, June 10th, 1873. Meteorological Societies.

\section{IRISH MEDICAL ASSOCIATION.}

To the Editor of THE LANCET.

SIR,-In justice to the Irish Medical Association, a society which for upwards of twenty years has been carrying on its useful operations, I claim of your well-known courtesy and fairness, space in the next issue of your paper to contradict the injurious misstatements of your Dublin correspondent referring to the last meeting of the Society, and which nothing but the most wilful ignorance, or something worse, on his part, could have induced him to publish.

Passing over the ill-natured question as to the annual meeting of the Society as unworthy of notice, I proceed to the statement "that the Council of the Society takes credit to itself for the work done by other societies." This is so vague an accusation that it is difficult to deal with it otherwise than by the simplest but most positive denial of its truth. The Council against which your correspondent makes this gross charge is composed of gentlemen of the highest standing in their profession, among whom are the President and three ex-presidents of the Royal College of Surgeons, and is a sufficient guarantee that any report drawn up with its approval would contain nothing but the most truthful statement of the business transacted by it during its official year, and I defy your correspondent to point out a single statement in the report that cannot be proved by the records of the Society. But your correspondent is guilty of another error in reference to the proposal made by the Society to form among its members some provision for the widows and children of Poor-law and dispensary medical officers. This scheme has now been for two sears under the consideration of the profession, and has been so fully canvassed and discussed by its promoters that the fact of your correspondent mixing up with it the Superannuation Act obtained by the Association two years ago as a provision for the worn-out medical officer (not for his widow), confirms my opinion that he did not take the trouble of being present at the meeting he so incorrectly describes and so unfairly maligns. Dublin, June 16th, 1873. Evant, E. J. Quinan, M.D. Hon. Sec., Irish Medical Association.

* * We have not had time to communicate with our Dublin correspondent on the subject of Dr. Quinan's letter, but feel sure he can give an explanation next week. -Ev. I.

\section{LIFE ASSURANCE COMBINED WITH SICK ALLOWANCE. \\ To the Editor of Ters LANCET.}

SiR,-Several letters have appeared in jour valuable paper lately, urging the establishment of a combined life assurance with sick allowance suitable for members of our profession.

Being one of the directors of the British Provident Life and Guarantee Association, at 96, London-wall, E.C, I brought the subject under the consideration of the board at our last meeting. It was unanimously resolved that the actuary should be instructed to prepare the necessary tables, especially bearing in mind Dr. Woodward's excellent suggestion that the amonnt at death should depend upon the sum drawn out as sick pay.

Our office is a young one, and our subscribed capital is small, but we have no debts, and are doing a good life business. We have an efficient staff, with good central offices, and nothing will be wanted for preliminary expenses beyond a little extra printing, advertising, and postage. 
We shall be glad to receive the active co-operation or the suggestions of any who are anxious to promote the scheme.

As soon as the tables are ready they shall, with other information, be sent on for your inspection. I believe that under proper management it can, not only be made a com. mercial success, but a great and lasting boon to the profession.

I am, Sir, yours, \&e.,

HenRt T. TRend, L.R.C.P.ED., \&c.

Petherton-road, Highbury New Park, June 17th, 1873.

\section{PARIS.}

(From our own Correspondent.)

I HAVE had occasion in previous letters to allude to the arrangements which were being carried out for the formation of a Superior Council of Public Education, to which considerable importance is attached, as it will have to deliberate and decide on all questions of educational reform. All the elections and nominations have now taken place, and the Council is complete. The members have been taken from all the great educational, scientific, religious, and administrative bodies of the country. The medical profession is more especially represented by Dr. Barth, elected by the Paris Academy of Medicine; Dr. Wurtz, elected by the three Medical Faculties of France; and Dr. Bouisson, the Dean of the Montpellier School of Medicine. Besides these three members, the composition of the Council is as follows:-Vice-President, M. Dumas, representing the Institute; the Dean of the Paris Faculty of Letters, M. Patin; three Inspector-Generals of Public Education, two Councillors of State, a General, an Admiral, two Archbishops, and two Bishops; the Dean of the Protestant Faculty of Theology of Montauban, M. Sardinous; the Pastor of the Church of Augsburg; the Great Rabbin of France; the First President of the Cour de Cassation ; three Members of the Institute; the Administrator of the Collége de France; M. Milne Edwards, Dean of the Paris Faculty of Sciences; three Members of the Superior Council of Agriculture and Commerce; the Director of the Museum of Natural History, M. Chevreuil; a Professor at the School of Law; and a Professor at the Faculty of Letters.

Dr. Decaisne is one of the most indefatigable workers here among those who are doing battle against absinthe, and, generally, alcohol in all its formidable shapes. A few days ago he began a new campaign, now directed against bitters, at the Academy of Sciences. People said: "It's all well and good; absinthe, we must admit, is deadly; but then we have got bitters. That's a resource, and so harmless." Dr. Decaisne answers "No," and in his communication to the Academy, after a long investigation of the subject, he boldly enunciates several conclusions which must sadly disappoint and terrify all bitters-drinkers. As in respect of absinthe and vermouth, Dr. Decaisne is convinced that the bitter, aromatic, and exciting plants which enter into the composition of bitters, develop in a marked degree and enhance the mischievous effects of alcohol. These effects are of course heightened when, as so often happens, bitters is fabricated with spoilt herbs and alcohol of bad quality, to disguise the taste of which strong acids are employed. Dr. Decaisne thinks that the alcohol extracted from beetroot, potatoes, and corn, and which is so commonly used for the fabrication of bitters, is much more harmful than alcohol made out of wine. He therefore condemns bitters because, both on account of the character of the plants and the strength and bad quality of the alcohol, it is a drink which promptly brings on acute and chronic alcoholism. "Epileptiform fits," says Dr. Decaisne, "may be equally caused by the abuse of absinthe, vermouth, bitters, chartreuse, and even some adulterated white wines"; and, to avoid even the slightest risk, he concludes that the use of bitters, even when of good quality and for the sake of "getting an appetite," must be abandoned.

At one of the last sittings of the Municipal Council, the administration of the Assistance Publique sent in a demand for supplies to take such measures as may prevent the pretty little maritime hospital of Berck-sur-Mer from being destroyed by the sea. Berck-sur-Mer is quite a model hospital, which was built on the seaside for the purpose of receiving convalescent and scrofulous children, after the plan which was started in Italy, and has been so very successful there. At the time the hospital was built it was complained that it was too far from the sea, and that this was a great inconvenience. Now the sea has gained ground after various works which have been done by the Government at the mouth of the Athie (a river near there), and the Assistance Publique has been obliged to send some men into Holland to study the system of dykes, and is asking the Municipal Council for a grant, as the hospital belongs to the town of Paris.

I have to record with regret the melancholy death of $M$. Bricheteau, the talented and esteemed editor of the Bulletin de la Thérapeutique, at a comparatively early age. Dr. Bricheteau was universally liked for his geniality and kindness of manner. He was a distinguished worker and an elegant writer, but had been unfortunate in his concours, chiefly through excessive timidity of character; and this failure, when people considered and he himself knew that he was worthy of the highest posts, told deeply on his character and health. For the last two or three years he had been obliged to give up his editorial duties on the Bulletin, and seek for health in retirement from the busy struggle of professional life in Paris. But his constitution gave way gradually, and he has just died in the last stage of an affection of the nervous centres.

The Society of Temperance, or French association against the abuse of alcohol, held its annual meeting on Sunday last. Mr. Hippolyte Passy, member of the Institute, occupied the chair, and the meeting was well attended. The proceedings of the day included a report by Dr. Lunier on the progress and action of the association; a report on the prizes which are to be given away in 1873 , by M. Bertrand and Dr. Magnan, the well-known author of " Researches on the Comparative Effects of Alcohol and Absinthe"; a communication by Dr. Foville on the American asylums for drunkards; and several questions of minor interest.

At the last sitting of the Société de Biologie an interesting communication was made by MM. Jolyet and Blanche, on the results of various experiments which they had conducted with nitrous oxide. Some of the experiments had been made with the seeds of watercresses; these had been put on a bit of moist paper under a glass containing pure protoxide of nitrogen. No germination took place, but on lifting up the glass a little so as to allow air to enter, the seed germinated, and two days after a small stalk began to appear. Other experiments were made on animals; birds and frogs had been subjected to the influence of the gas, and death had supervened rapidly after a few minutes, or even a few seconds. In all the experiments sensibility had persisted until the end. At the postmortem the blood of the heart and arteries was black. The authors concluded that " protoxide of nitrogen does not keep up the combustion of animals or plants, and that it produces anæsthesia only through asphyxia, when the animal is in imminent danger of death." Dr. Charcot remarked that he had seen the gas administered only once, and that it was a most formidable tableau; the face was livid and presented the aspect of approaching death, or of some forms of epilepsy; yet life came back rapidly, and there had been no accident. M. Blot alluded to cases of death, all of which had not been published. M. Laborde had seen the gas applied in a case of confinement; he did not know why it should be called laughing gas, as the poor woman had let fall torrents of tears. Claude Bernard recalled the experiments of Boussingault; leaves of plants put under a glass filled with pure carbonic acid had not decomposed the gas, but on introducing a certain quantity of oxygen the usual phenomena had taken place.

Paris, June, 1873.

Ergot of RYe in Headache.-Dr. Silver, of Sidney, Ohio, uses the liquid extract in doses of from ten to twenty drops every half hour until relief is obtained, or until four or five doses have been taken.-Philadelphia Medical and Surgical Reporter. 